\title{
Enhancing the Productivity of a Roof-Type Solar Still Utilizing Alumina Nanoparticles and Vacuum Pump
}

\author{
Eslam Mutlq ${ }^{1 *}$, Mohammad Hamdan' ${ }^{1}$ Jamil Al Asfar ${ }^{1}$ \\ 1 Mechanical Engineering Department, the University of Jordan, Amman 11942, Jordan \\ * Corresponding author's e-mail: eslam92.mutlq@gmail.com
}

\begin{abstract}
Unlike conventional fresh water producing systems, from saline or brackish water, the innovative solar water producing systems are efficient and effective. Experiments were conducted on two identical roof-type solar stills and simultaneously tested under the same weather conditions. One of these stills was modified by integrating a vacuum pump to lower the pressure inside while the other still was used as a reference unit. Different concentrations of $\mathrm{Al}_{2} \mathrm{O}_{3}$ nanoparticles were chosen, $0.2 \%, 0.4 \%$, and $0.6 \%$, and used with water inside the modified still. It was verified that the modified still, without nanoparticles, yields $34.84 \%$ more production than the conventional still. In addition, the modified still with a $0.4 \%$ of $\mathrm{Al}_{2} \mathrm{O}_{3}$ nanoparticles produced the highest percentage of distilled water, $44.42 \%$ in comparison to the one without the use of $\mathrm{Al}_{2} \mathrm{O}_{3}$ nanoparticles, followed by $37.94 \%$ and $24.07 \%$ for $0.6 \%$ and $0.2 \%$ of $\mathrm{Al}_{2} \mathrm{O}_{3}$ nanoparticles, respectively.
\end{abstract}

Keywords: solar still, vacuum pump, nanoparticles, water desalination

\section{INTRODUCTION}

Solar stills can be placed at each house for producing at least potable water. They are economical and inexpensive, simple in design, and pollution free. Yet, there is a serious challenge that is associated with solar stills which is the relatively small-amount of fresh water produced. The latter is affected by a set of factors that influence the evaporation rate inside stills system such as temperature and pressure. As the temperature of the system increases, more water evaporates from the surface of the water basin. Simultaneously, as the pressure of the system decreases, the saturation temperature decreases which causes water to vaporize at a relatively low temperature [2].

Many endeavors have been made various experimental techniques to improve the performance of solar stills utilizing. One of these techniques is the use of nanotechnology in fluids to improve heat transfer properties. Heat transfer plays the main role in different applications; such as air-conditioning, power generation, and transportation. Since a good thermal conductivity performance is widely required for different applications, serious attempts were aimed to improve the thermal conductivity of working fluids. Nanotechnology attracts wide attention in this domain, as it directly affects the thermal conductivity of fluids.

Sriram, et al. [11] assembled and tested a double slope-type solar still while maintaining a low pressure inside its system. By maintaining a low pressure inside the system, it was found that the distilled water production was enhanced by $50.75 \%$. Likewise, by utilizing a black cloth as a basin material, there was an increment in the distilled water production by $88.66 \%$.

Badran, et al. [2] exhibited an experimental design for a basin-type solar still modified by vacuum while a low pressure was maintained inside the system by using a simple compressor. It was found that the accumulated purified water production for one day was $1.2 \mathrm{~L} / \mathrm{m}^{2}$ with a distillation efficiency of $15 \%$.

Gnanadason, et al. [4] tested a single basin solar still that is made of copper sheets. The still was modified by maintaining a low pressure inside its 
system. The result was a distilled water production of $2.56 \mathrm{~L} /$ day.

Elango, et al. [3] debated the impact of utilizing alumina, zinc oxide, iron oxide, and tin oxide nanoparticles on the purified water production for a single slope solar still. Alumina nanofluid has the highest purified water production compared with water only. In addition, the payback period of the still that contained alumina nanofluid was 2.85 years.

Sahota and Tiwari [9] discussed the impact of utilizing different types of nanofluids on the purified water production for a double slope solar still. It was implied that the still produces a higher rate of purified water at different weather conditions when utilizing $\mathrm{Al}_{2} \mathrm{O}_{3}$ nanofluid followed by $\mathrm{TiO}_{2}$ and $\mathrm{CuO}$ nanofluids compared with using water only.

Sharshir, et al. [10] assessed the impact of utilizing flake graphite nanoparticles and water depth on the refined water production for a solar still. The result was that the refined water production was improved by $50.28 \%$. In addition, it was noted that the refined water production decreases as the depth of saline water increases.

Rufuss, et al. [8] assessed the impact of utilizing copper oxide nanoparticles impregnated in phase change material (NPCM) on the performance of the solar still. The copper oxide nanoparticles were impregnated in paraffin and utilized as a latent heat energy storage medium in the solar still. It was found that the solar still with NPCM improved the production of distilled water by $35 \%$ in relation to the still with PCM only.

Abdelal and Taamneh [1] investigated the impact of utilizing various absorber plates made of carbon fiber/epoxy composites integrating either carbon nanotubes or graphene nanoplatelets on the performance of a pyramid solar still. They used four pyramid-type solar stills and tested them under Jordanian climatic conditions. It was verified that impregnating $2.5 \%$ and $5 \%$ volume fractions of carbon nanotubes in the carbon fiber/ epoxy composites improved the distilled water production by $65 \%$ and $109 \%$, respectively, compared with the normal type of the absorber plate. In addition, integrating a $2.5 \%$ volume fraction of graphene nanoplatelets in the epoxy material increased the productivity of the still by $30 \%$.

Haddad, et al. [5] studied the impact of utilizing a vertical rotating wick (VRW) on the productivity of a basin type solar still. The enhancement of the solar still productivity was introduced through a comparative study with and without using VRW in the still. It was found that utilizing VRW in the still during summer season improved the distilled water production by $14.72 \%$, compared with the conventional still (without VRW). During the winter season, the productivity of the still was enhanced by $51 \%$, compared with the conventional still.

Kabeel, et al. [6] investigated the effect of adding nanomaterials to the black paint of the solar still walls. They selected the cuprous oxide as a nanoparticles material and adding it to the black paint. The results showed that the distilled water production was enhanced by $25 \%$ at a volume fraction of $40 \%$ of cuprous oxide nanoparticles compared with the conventional still. In addition, the payback period was about 96 days for the modified still at a volume fraction of $10 \%$ of cuprous oxide nanoparticles compared with 89 days for the conventional still.

The current study investigated the effect of using alumina nanoparticles under low pressure on the productivity of a roof-type solar still. Two identical roof-type solar stills were assembled and tested simultaneously, under the same weather conditions. One of these stills contained nanoparticles mixed with water and was modified by integrating a simple vacuum pump connected with a simple external condenser. The other one contained water only and had no modifications. $\mathrm{Al}_{2} \mathrm{O}_{3}$ nanoparticles were selected at the concentrations of $0.2 \%, 0.4 \%$, and $0.6 \%$ and used with water inside the modified still.

\section{EXPERIMENTAL SETUP}

The main components used in this work are two roof-type solar stills, a data acquisition system, a weather station, and a vacuum pump. Each one of both solar stills consisted of a glass cover, internal galvanized iron sheets, and external galvanized iron sheets. Figures 1 and 2 show a schematic diagram for both conventional and the modified solar stills respectively; as indicated, the latter contains $\mathrm{Al}_{2} \mathrm{O}_{3}$ nanoparticles and is additionally connected to a vacuum pump to maintain a low pressure inside the still.

Four triangular glass plates were compounded together forming a pyramid shape to cover the upper side of the still. This glass cover has a thickness of $6 \mathrm{~mm}$. Each glass plate of the glass cover has a width of $50 \mathrm{~cm}$, a height of $40 \mathrm{~cm}$, and 


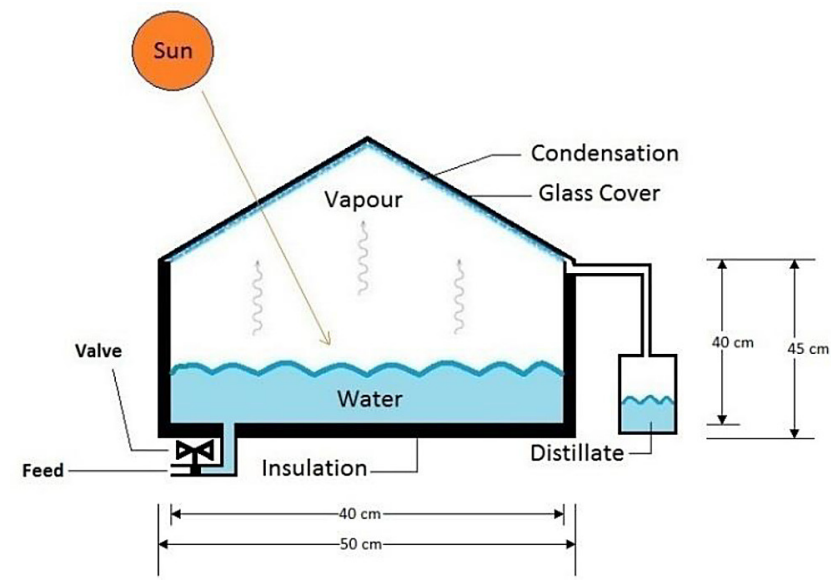

Figure 1. A schematic diagram of the conventional still

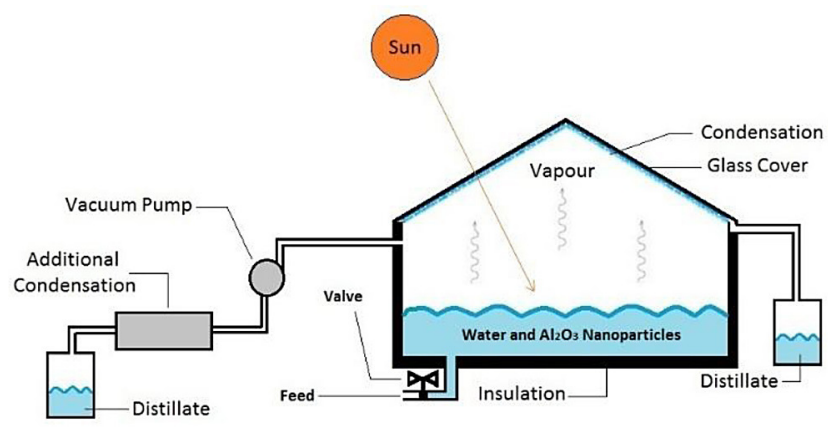

Figure 2. A schematic diagram of the modified still

a sloping angle of $47.1^{\circ}$. The $1.8 \mathrm{~mm}$-thick internal galvanized iron sheets were compounded together forming a closed box with a base area (absorber area) of $0.16 \mathrm{~m}^{2}(0.4 \times 0.4 \mathrm{~m})$, and a height of $40 \mathrm{~cm}$. Furthermore, the $0.9 \mathrm{~mm}$-thick external galvanized iron sheets were compounded together forming the outer surface with a base area of $0.25 \mathrm{~m}^{2}(0.5 \times 0.5 \mathrm{~m})$, and a height of $45 \mathrm{~cm}$.

A data acquisition system placed next to both solar stills was utilized to measure the temperatures of the glass cover, vapor, and water for both stills. It was also used to measure the ambient temperature. In addition, a controller in the data acquisition system was connected to a pressure sensor placed inside the modified still. The role of the controller was to control the vacuum pump to be switched on and off depending on a certain pressure value. The pressure was maintained inside the modified still at $75 \mathrm{kPa}$.

The production of distilled water was taken on an hourly basis during the daytime period and as an accumulated production during the nighttime period. The total production of distilled water for each still per day constituted the daytime production plus the nighttime production.

\section{RESULTS AND DISCUSSION}

The first step in this work was to find the optimum concentration of nanoparticles that yields the maximum condensate. Figure 3 shows that the maximum daily production of fresh water (over 24-hours) was $1646.25 \mathrm{ml} / \mathrm{m}^{2}$ at a concentration of $0.4 \%$ of $\mathrm{Al}_{2} \mathrm{O}_{3}$ nanoparticles, followed by $1474.375 \mathrm{ml} / \mathrm{m}^{2}$ and $1205 \mathrm{ml} / \mathrm{m}^{2}$ for $0.6 \%$ and $0.2 \%$ concentrations of $\mathrm{Al}_{2} \mathrm{O}_{3}$ nanoparticles, respectively. In addition,, the modified still without using nanoparticles yields $915 \mathrm{ml} / \mathrm{m}^{2}$ compared to $596.25 \mathrm{ml} / \mathrm{m}^{2}$ produced by the conventional still.

Figure 4 shows the percentage enhancement of applying vacuum inside the modified still compared to the conventional still. As can be seen from the figure that the use of vacuum technique improves the production of distilled water by $34.84 \%$.

The percent increase in distilled water production for the modified still with and without using $\mathrm{Al}_{2} \mathrm{O}_{3}$ nanoparticles was compared in figure 5 .

It is clear from the figure that the optimum concentration of $\mathrm{Al}_{2} \mathrm{O}_{3}$ nanoparticles that has the highest percentage is $0.4 \%$. Consequently, 


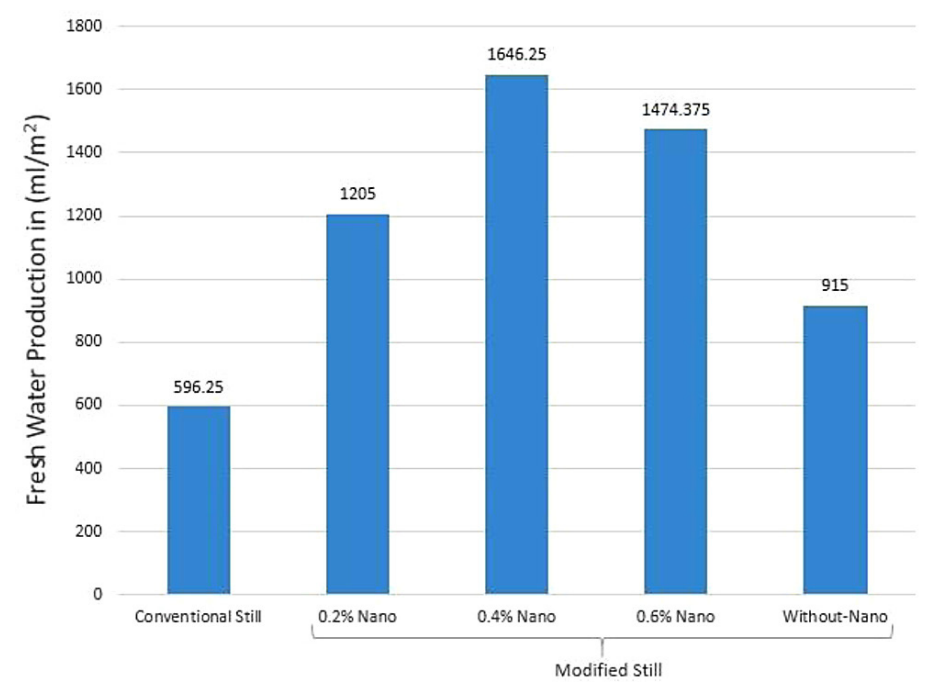

Figure 3: Total daily production of distilled water for both modified and the conventional stills.

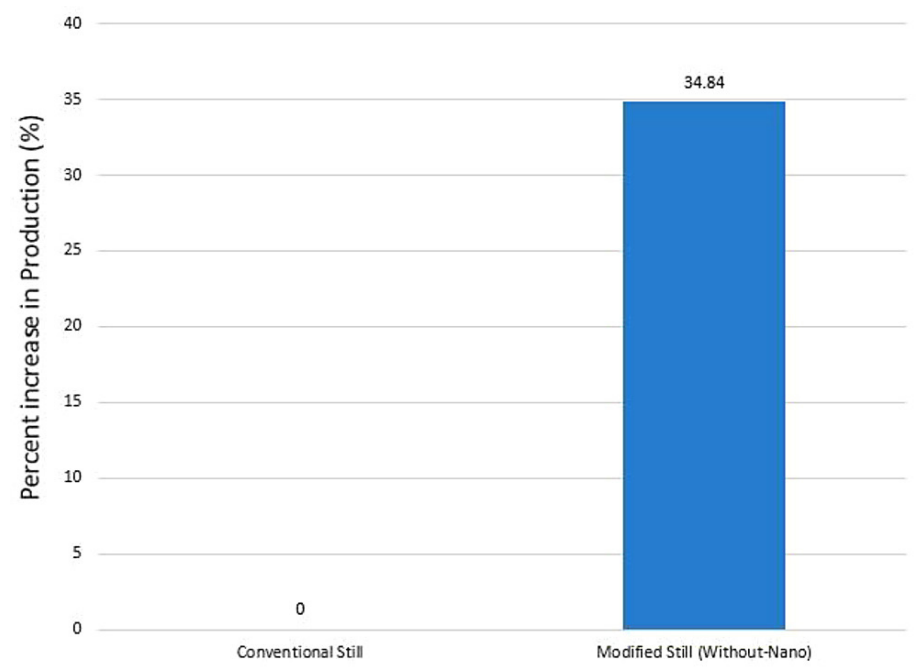

Figure 4: Percent increase in the production of distilled water for both modified and the conventional stills.

in the remaining work, the concentration of nanoparticles used was $0.4 \%$.

Figure 6 shows a comparison between the hourly productions of distilled water for both modified and the conventional stills. In addition, it presents the hourly solar radiation over the daytime period.

It was revealed that the maximum hourly production of fresh water by the modified still at a concentration of $0.4 \%$ of $\mathrm{Al}_{2} \mathrm{O}_{3}$ nanoparticles was $232.5 \mathrm{ml} / \mathrm{m}^{2}$ obtained at 18:00.

As can be seen from the figure, the distilled water production by the modified still increased gradually to $62.5 \mathrm{ml} / \mathrm{m}^{2}$ at $11: 00$, and then it fell to $17.5 \mathrm{ml} / \mathrm{m}^{2}$ at $12: 00$. Afterwards, there were fluctuations until 15:00. Between 15:00 and 17:00, there was a steady increase from about $12 \mathrm{ml} / \mathrm{m}^{2}$ to $50 \mathrm{ml} / \mathrm{m}^{2}$. Then, the production amount rose dramatically reaching the maximum value of $232.5 \mathrm{ml} / \mathrm{m}^{2}$ at 18:00. This decrease in the productivity is attributed to the fact that the increase of the water vapor pressure inside the basin (due to the vaporization of water) will act negatively on the amount of evaporated water.

It is also noted that the production of fresh water during sunset was high for both solar stills. The latter can be explained by examining the distribution of both water and glass cover temperatures for both stills over the daytime period. Figures 7 and 8 show temperatures of both water and glass cover for both modified and the conventional stills, respectively. The figures illustrate that during the morning and afternoon, the temperature of the glass cover was high and greater than that of water. During sunset, the temperature of the glass cover was lower than that of water. As a result, there was a higher condensation rate on the inner surface of the glass cover. 


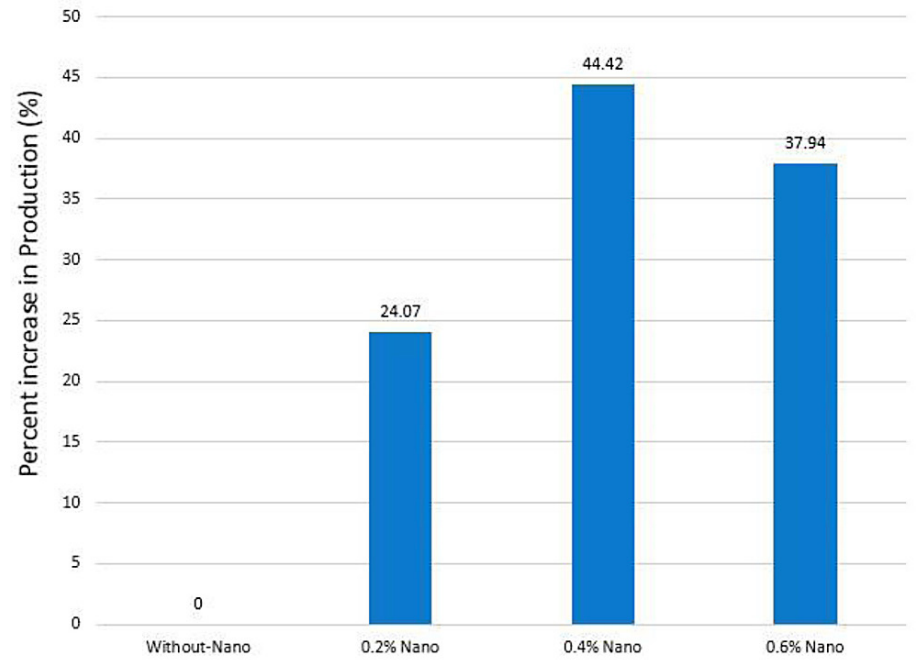

Figure 5: Percent increase in the distilled water production for the modified still at different $\mathrm{Al}_{2} \mathrm{O}_{3}$ nanoparticles concentrations.

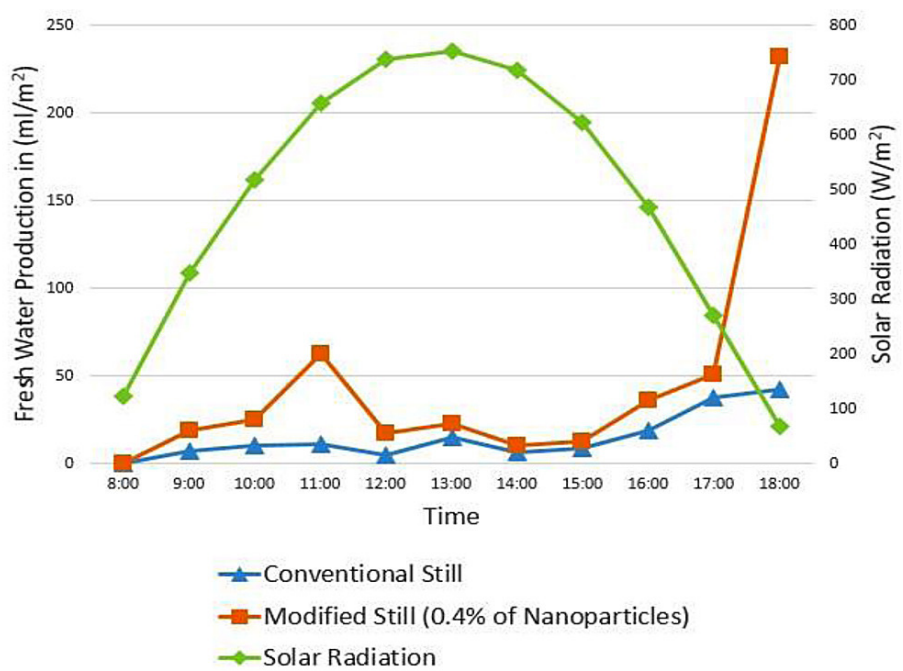

Figure 6. Variations of distilled water production for both solar stills when using $0.4 \%$ of $\mathrm{Al}_{2} \mathrm{O}_{3}$ nanoparticles with the modified one.

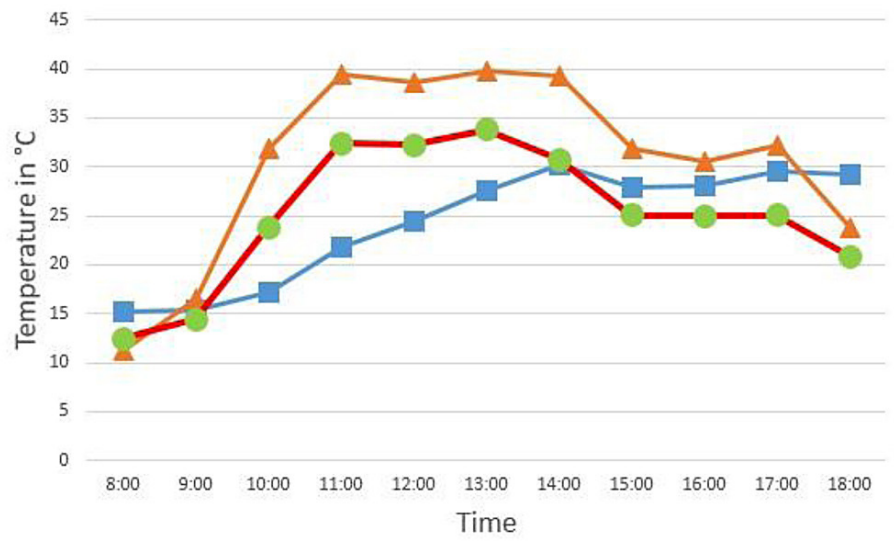

-W-Water-Nano Temp. $\quad$-Glass Temp. $\quad$--Ambient Temp.

Figure 7. Temperatures of both water and glass cover for the modified still at a concentration of $0.4 \% \mathrm{Al}_{2} \mathrm{O}_{3}$ nanoparticles. 


\section{COST ANALYSIS}

The cost analysis for both systems is presented in table 1 . The use of $0.4 \%$ of $\mathrm{Al}_{2} \mathrm{O}_{3}$ nanoparticles with the modified still yields a higher distilled water production than the conventional still, which justifies a higher investment. In addition, the payback period of the modified still is 2.76 years, which is shorter than that of the conventional still.

\section{UNCERTAINTY ANALYSIS}

Different parameters were measured during the experiments for evaluating the system performance. The parameters include the temperature at different points of both stills (saline water and the glass cover), ambient temperature, the pressure inside the modified still, solar radiation, and finally the amount of distilled water.

Various specialized equipment was used to measure the parameters as accurately as possible. The temperatures were measured using LM 35 type thermocouples $\left( \pm 0.4^{\circ} \mathrm{C}\right)$ that were connected to a digital temperature indicator. A thin-film pressure transducer with a bar range (0-10) and an accuracy of $\pm 0.5 \%$ FS was used to measure the pressure inside the modified still. The total insolation was measured using a CMP11-L A pyranometer with a $0-4000 \mathrm{~W} / \mathrm{m}^{2}$ range and a reading accuracy of \pm $2 \%$. A $500 \mathrm{ml}$ flask accurate to $\pm 5 \mathrm{ml}$ was used to measure the hourly yield.

On the basis of the accuracy of each measuring unit, the estimation of the uncertainty in measurements was carried out following the procedure explained by Kline and McClintock [7]. It was found out that the uncertainty in measurements is about $2.33 \%$.

\section{CONCLUSION}

The effect of using $\mathrm{Al}_{2} \mathrm{O}_{3}$ nanoparticles under low pressure on the performance of the roof-type solar still was investigated. The main conclusions may be summarized as follows:

1. The performance of the roof-type solar still was enhanced when using $\mathrm{Al}_{2} \mathrm{O}_{3}$ nanoparticles under low pressure.

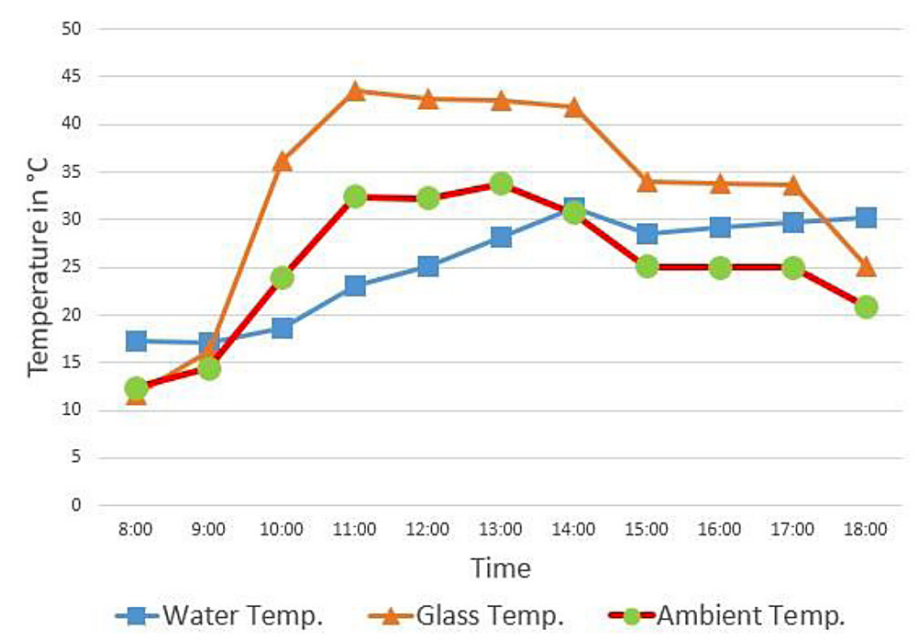

Figure 8: Temperatures of both water and glass cover for the conventional still.

Table 1: Cost Analysis for both modified and the conventional solar stills.

\begin{tabular}{|l|c|c|c|}
\hline \multicolumn{1}{|c|}{ Factor } & Conventional still & $\begin{array}{c}\text { Modified still with } 0.4 \% \text { of } \mathrm{Al}_{2} \mathrm{O}_{3} \\
\text { nanoparticles }\end{array}$ & Unit \\
\hline Fabrication Cost & 280 & 450 & US $\$$ \\
\hline Yearly Usage & 300 & 300 & Days \\
\hline Production Per Day & 0.62125 & 1.64625 & $\mathrm{~L} / \mathrm{m}^{2} / \mathrm{m}^{2} /$ year \\
\hline Total Production & 186.375 & 493.875 & US $\$ / \mathrm{L}$ \\
\hline Litre Price & 0.33 & 0.33 & US $\$$ \\
\hline Total Cost Saved & 61.5 & 162.98 & Years \\
\hline Payback Period & 4.55 & 2.76 & \\
\hline
\end{tabular}


2. The optimum concentration of $\mathrm{Al}_{2} \mathrm{O}_{3}$ nanoparticles that yields the maximum fresh water production was $0.4 \%$.

3. The maximum production of distilled water corresponds to the use of $0.4 \%$ of $\mathrm{Al}_{2} \mathrm{O}_{3}$ nanoparticles with the modified still by an amount of $1646.25 \mathrm{ml} / \mathrm{m}^{2}$ followed by $1474.375 \mathrm{ml} / \mathrm{m}^{2}$ and $1205 \mathrm{ml} / \mathrm{m}^{2}$ for $0.6 \%$ and $0.2 \%$ of $\mathrm{Al}_{2} \mathrm{O}_{3}$ nanoparticles, respectively.

4. The modified still, without nanoparticles, yields $34.84 \%$ more production than the conventional still.

5. The modified still with a $0.4 \%$ of $\mathrm{Al}_{2} \mathrm{O}_{3}$ nanoparticles produced the highest percentage of distilled water, $44.42 \%$ in comparison to without using $\mathrm{Al}_{2} \mathrm{O}_{3}$ nanoparticles, followed by $37.94 \%$ and $24.07 \%$ for $0.6 \%$ and $0.2 \%$ of $\mathrm{Al}_{2} \mathrm{O}_{3}$ nanoparticles, respectively.

6 . The cost analysis showed that the payback period of the modified still with a $0.4 \%$ of $\mathrm{Al}_{2} \mathrm{O}_{3}$ nanoparticles is 2.76 years, which is shorter than that of the conventional still.

\section{REFERENCES}

1. Abdelal, N. and Taamneh, Y. 2017. Enhancement of pyramid solar still productivity using absorber plates made of carbon fiber/CNT-modified epoxy composites. Desalination, 419, 117-124.

2. Badran, O. Beithou, N. Al Alawin, A. Awad, A., Abdelhadi, Y. and Al-Mofleh, A. 2013. Experimental Study of a Vacuumed Solar Still System. International Journal of Applied Power Engineering, 2(3), 99-104.
3. Elango, T., Kannan, A. and Murugavel, K.K. 2015. Performance study on single basin single slope solar still with different water nanofluids. Desalination, 360, 45-51.

4. Gnanadason, M.K. Kumar, P.S. Wilson, V.H. and Kumaravel, A. 2015. Productivity Enhancement of a single basin solar still. Desalination and Water Treatment, 55(8), 1998-2008.

5. Haddad, Z. Chaker, A. and Rahmani, A. 2017. Improving the basin type solar still performances using a vertical rotating wick. Desalination, 418, 71-78.

6. Kabeel, A.E. Omara, Z.M. Essa, F.A. Abdullah, A.S. Arunkumar, T. and Sathyamurthy, R. 2017. Augmentation of a solar still distillate yield via absorber plate coated with black nanoparticles. Alexandria Engineering Journal, 56(4), 433-438.

7. Kline, S.J. and McClintock, F.A. 1953. Describing Uncertainties in Single Sample Experiments. Mech. Eng., 75, 3-8.

8. Rufuss, D.D.W. Iniyan, S. Suganthi, L. and Davies, P.A. 2017. Nanoparticles Enhanced Phase Change Material (NPCM) as Heat Storage in Solar Still Application for Productivity Enhancement. Energy Procedia, 141, 45-49.

9. Sahota, L. and Tiwari, G.N. 2016. Effect of nanofluids on the performance of passive double slope solar still: A comparative study using characteristic curve. Desalination, 388, 9-21.

10. Sharshir, S.W., Peng, G., Wu, L., Essa, F.A., Kabeel, A.E. and Yang, N. 2017. The effects of flake graphite nanoparticles, phase change material, and film cooling on the solar still performance. Applied Energy, 191, 358-366.

11. Sriram, V. Hansen, R.S. and Murugavel, K.K. 2013. Experimental Study a Low Pressure Solar Still. Applied Solar Energy, 49(3), 137-141. 